\title{
Antibodies to Human Thymic Epithelium Form Part of the Murine Autoreactive Repertoire
}

\author{
JONA FREYSDOTTIR* and MARY A. RITTER ${ }^{\dagger}$ \\ Dept. of Immunology, Imperial College School of Medicine, Hammersmith Hospital, Du Cane Road, London W12 ONN, England
}

\begin{abstract}
Monoclonal antibody (mAb) MR6 recognises a $200 \mathrm{kDa}$ glycoprotein, gp200-MR6, which is expressed at high levels on the surface of human thymic cortical epithelium. In order to produce further mAbs against the gp200-MR6 molecule, mice were immunised with purified human gp200-MR6, hybridomas produced and supernatants screened for MR6-like reactivity on human thymic sections. Surprisingly this conventional hybridoma technique failed to produce stable hybridoma cells producing MR6-like antibodies. However, antibodies with specificities other than MR6-like were obtained. Three such antibodies (1B2, 3A3 and 4B3) were analysed further. Expression of 1B2-antigen, 3A3-antigen and 4B3-antigen was analysed on skin, tonsil and thymic sections, on cultured thymic epithelial cells (TEC), thymocytes and peripheral blood mononuclear cells (PBMC), and found to be expressed by both lymphocytes and epithelial cell populations. Furthermore, the antigens were also expressed on mouse thymic, epithelial cells. The regulation of expression of these antigens was analysed following mitogen or cytokine stimulation of PBMC and cultured TEC, respectively. Expression on T cells was clearly affected by mitogens that mimic activation through the $T$ cell receptor and expression on cultured TEC was affected by T cell-derived cytokines. Thus, the shared epithelial-lymphocyte molecules identified in this study may play a role in the cross-talk between the developing thymocytes and their epithelial microenvironment. The production of $\mathrm{mAbs}$ with specificities other than that of purified gp200-MR6 indicates that a wide range of B cells with specificity for components of the human thymic microenvironment exist in the normal mouse. These may detect epitopes that are shared with common pathogens to which the animals are exposed. Alternatively, they may be autoreactive B cells that are normally silent in the absence of $\mathrm{T}$ cell help. This help may be provided by $\mathrm{T}$ cells specific for human gp200-MR6, or nonspecifically by polyclonal activation induced by the adjuvant.
\end{abstract}

Keywords: Autoantibodies, Epithelium, Microenvironment, Monoclonal Antibodies, Thymus

Abbreviations: Con A, concanavalin A, CTES, cluster of thymic epithelial staining, GlcNAc, $\mathrm{N}$-acetyl- $\beta$-D-glucosamine, mAb, monoclonal antibody, MFI, mean fluorescence intensity, PBMC, peripheral blood mononuclear cells, PHA, phytohemagglutinin, PMA, phorbol 12-myristate 13-acetate, PWM, pokeweed mitogen, TEC, thymic epithelial cells

\footnotetext{
* Present Address: Lyfjathroun hf, Biopharmaceutical Research, Geirsgata 9, 101 Reykjavik, Iceland.

$\dagger$ To whom correspondence should be addressed.
} 


\section{INTRODUCTION}

The thymic microenvironment plays an important role in thymocyte development by providing signals regarding migration, differentiation, selection and proliferation. These signals may be mediated by soluble molecules produced by the stromal cells or by direct cell-cell interaction between surface molecules on the stromal cells and the thymocytes. However, little is known about the molecular mechanism involved. One way of investigating such microenvironmental signals provided by the stromal cells is to analyse in detail their surface molecules using monoclonal antibody and phage display techniques (van Vliet et al., 1984; de Maagd et al., 1985; Boyd et al., 1993; Palmer et al., 1997). The reagents generated in these studies have revealed significant molecular heterogeneity within the epithelial component of the thymic microenvironment.

Antibodies raised against the thymic epithelium of a variety of species, including human, have been divided into five major clusters of thymic epithelial staining (CTES) patterns (Kampinga et al., 1989; Ritter and Crispe, 1992). CTES I antibodies are pan-epithelial, CTES II antibodies label subcapsular/perivascular and a major subpopulation of medullary epithelial cells, CTES III antibodies detect molecules on cortical epithelium, CTES IV antibodies label Hassall's corpuscles and all medullary epithelial cells, and CTES V reagents stain Hassall's corpuscles and sometimes a surrounding halo of medullary epithelial cells. However, for only few of these mAbs are their target antigens identified.

One such antibody is the mAb MR6. The molecule recognised by mAb MR6, gp200-MR6, is a $200 \mathrm{kDa}$ glycoprotein expressed at high levels on the surface of human cortical epithelium and at much lower levels on macrophages, dendritic cells and thymocytes (Larché et al., 1988a; Mat et al., 1990). Apart from the thymus the gp200-MR6 is expressed on peripheral lymphocytes and on epithelial cells in breast, colon and skin (Larché et al., 1988a; Al-Tubuly et al., 1996). Since gp200-MR6 is shared by thymocytes and epithelial cells it was a potential candidate as a molecule participating in cell-cell cross-talk between the thymocytes and the epithelium. Functional analysis revealed that addition of mAb MR6 to cultures of $\mathrm{T}$ cell clones partially inhibited both antigen- and IL-2-induced proliferation and completely blocked IL-4-induced proliferation in a dose-dependent manner and that mAb MR6 completely abrogated the IL-4-dependent production of specific antigen-induced IgE by B cells (Larché et al., 1988a, 1988b). This dramatic influence on IL-4-dependent functions suggested that the gp200-MR6 was linked to the IL-4 receptor. Furthermore, mAb MR6 has been found to inhibit alloreactivity, probably via a block in the expansion of IL-4 responsive/secreting Th2 helper T cells (Imami et al., 1994). However, recent studies suggest that although mAb MR6 may antagonise the proliferation effect of IL-4 on lymphocytes it appears to behave as an agonist for the differentiation effect of IL-4 on epithelial cells (Al-Tubuly et al., 1997).

These studies raised the interesting possibility that the gp200-MR6 molecule may be involved in differential signalling via the IL-4 receptor, and that its high expression on cortical epithelium may reflect an important role in maintenance/differentiation of the cortical thymic microenvironment via thymocyte-derived IL-4. However, since the gp200-MR6 contains $180 \mathrm{kDa}$ of protein it is likely that the molecule contains more than one functional domain. Further studies would, therefore, be greatly facilitated by the development of mAbs to different regions of the gp200-MR6. Therefore, in order to be able to study the structure and function of the molecule further and to elucidate its link with the IL-4 receptor, mice were immunised with purified gp200-MR6 and their splenocytes used to produce hybridoma cells producing new monoclonal antibodies against gp200-MR6. Surprisingly, although no anti-gp200-MR6 secreting cells survived, several hybridoma cell lines secreting antibodies with specificities other than those that were MR6-like were obtained indicating that antibodies to thymic epithelium may form part of the murine autoreactive repertoire. 


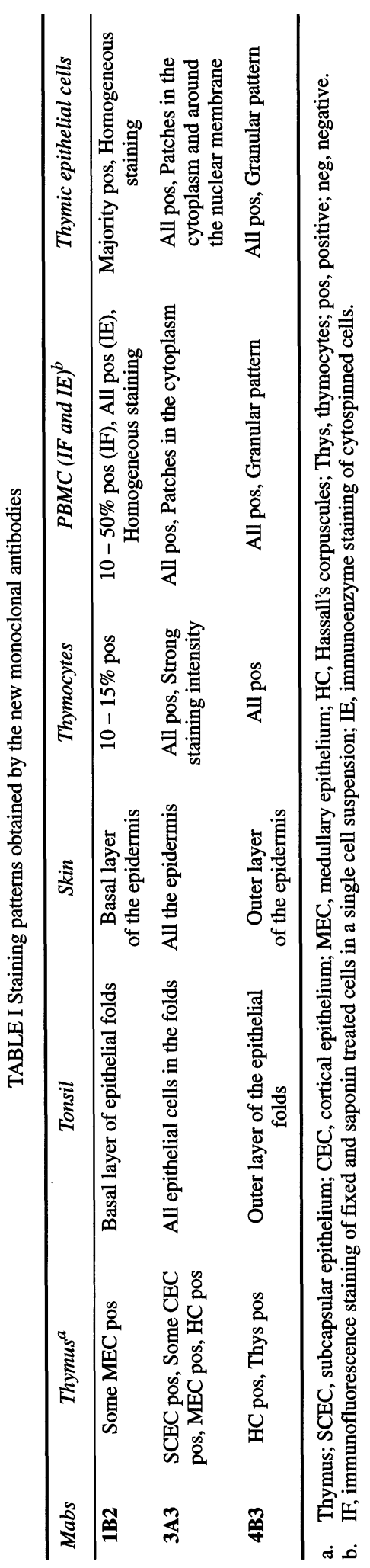




\section{RESULTS}

\section{Production of new Monoclonal Antibodies against Gp200-MR6}

Immunisation with purified human gp200-MR6 resulted in highly immunised mice, as confirmed by testing sera or ascites obtained from these mice. Subsequently, hybridoma cells secreting MR6-like antibodies were produced. This was confirmed by testing the hybridoma supernatants on thymic tissue sections. Unfortunately, these hybridoma cells always died, usually during the first cloning procedure, when cells had started to proliferate in the small wells in the 96 well plates.

\section{Production of new Monoclonal Antibodies with Different Specificities than MR6-like}

Screening the hybridoma cell supernatants on human thymic sections allowed detection of antibodies with specificities other than those that were MR6-like. Interestingly, hybridomas secreting antibodies with various specificities were detected. Amongst these were antibodies staining the thymocytes, different populations of thymic epithelium, thymocytes and epithelium, macrophages or dendritic cells, blood vessels and soluble particles around them, and finally antibodies that stained all cells as well as the intercellular areas.

Three hybridomas which stained different subpopulations of thymic epithelium were selected for further studies, 1B2, 3A3 and 4B3. These hybridomas were cloned at least three times, the last time with 0.3 cells per well. When single clones were obtained these were grown in bulk and a large amount of supernatant collected.

\section{Distribution of the Molecules Recognised by the new Monoclonal Antibodies}

Human thymic, skin and tonsil sections, PBMC, thymocytes, and cultured thymic epithelial cells were stained with the new monoclonals, in order to analyse the distribution of the molecules they recognise within lymphoid and non-lymphoid organs (table I). For comparison, mouse thymic epithelial cells were also stained with the new monoclonals.

\section{Expression within the thymus}

The expression of the molecules that were recognised by the new antibodies was studied on thymic sections (table I, figure 1). MAb 1B2 stained only some medullary epithelial cells. MAb 3A3 stained subcapsular, medullary and some cortical epithelial cells, as well as Hassall's corpuscles; it also stained thymocytes very weakly. MAb 4B3 stained Hassall's corpuscles very strongly and also thymocytes. No staining on thymocytes or epithelium was observed with the isotype matched antibody mAb 8D4 (data not shown).

\section{Expression within other tissues than thymus}

All three monoclonal antibodies stained tonsil and skin sections (table I, figure 2). MAb 1B2 stained the basal layer of the epidermis (basal epithelium) and the basal cell layer of the epithelial folds within the tonsil (figures 2A and 2B). MAb 4B3, on the other hand, stained mostly the upper layer of the epidermis (squamous epithelium) and the outer cell layer of the epithelial folds within the tonsil (figures $2 \mathrm{E}$ and $2 \mathrm{~F}$ ). $\mathrm{MAb} 3 \mathrm{~A} 3$ stained more or less all the epithelial cells in the skin and tonsil (figures $2 \mathrm{C}$ and 2D), with a similar staining distribution as that observed for cytokeratins (figures $2 \mathrm{I}$ and $2 \mathrm{~J}$ ). No staining of the epithelium was observed with the isotype matched control (mAb 8D4) although blood vessels in the tonsils were positive (figures $2 \mathrm{G}$ and $2 \mathrm{H}$ ). MAbs $1 \mathrm{~B} 2$, $3 \mathrm{~A} 3$ and $4 \mathrm{~B} 3$ all stained the cytoplasm, although an apparent surface staining was observed for mAb $3 \mathrm{~A} 3$ on squamous epithelium in the skin.

\section{Expression on thymocytes and PBMC}

Expression of the molecules recognised by the new monoclonal antibodies was analysed on/in PBMC from three healthy individuals and on thymocytes from two paediatric thymuses. Expression of all the antigens was found to be intracellular, both when cells were analysed by immunofluorescence and flow 

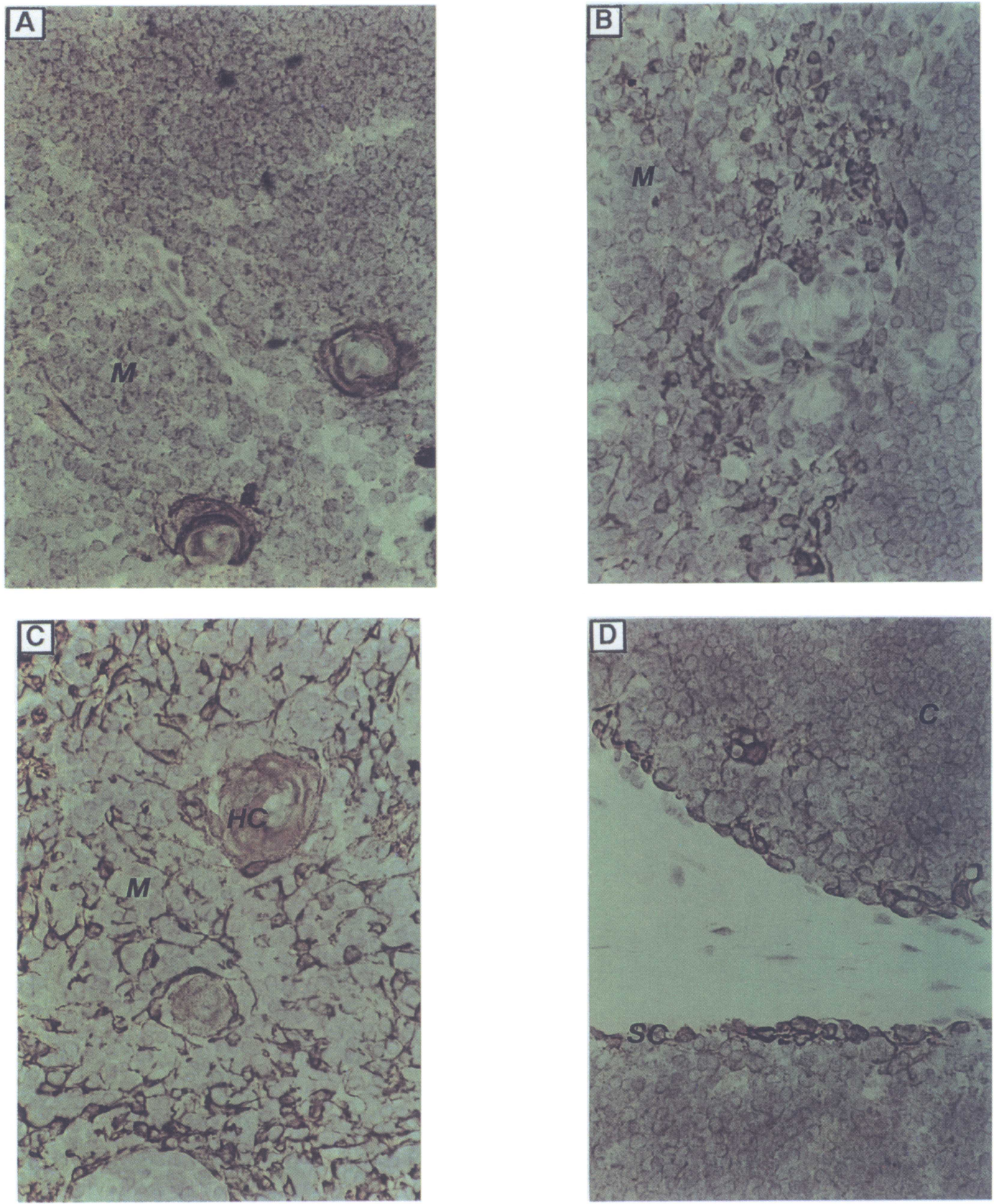

FIGURE 1 Human thymic sections stained by indirect immunoperoxidase with: mAb 4B3 which labels Hassall's corpuscles and thymocytes (A); mAb 1B2 showing labelling of medullahy epithelium (B); mAb 3A3 which labels medullary, subcapsular and some cortical epithelial cells $(C$ and D). Magnification $\times 380$. C, cortex; HC, Hassall's corpuscles; M, medulla; SC, subcapsule (See Color Plate I at the back of this issue)

cytometry on fixed cells (table I, figure 3 ) or by immunoenzyme staining of cytospins (table I, figure 4). No surface staining was detected by flow cytometry on unfixed cells. Expression of 1B2-anti- 
gen varied between individuals, with 10 to $50 \%$ of PBMC and thymocytes being positive when analysed by immunofluorescence, although cytospin analysis indicated that essentially all cells contained the 1B2-antigen. All PBMC expressed the 3A3-antigen and 4B3-antigen when analysed on cytospins and approximately $80 \%$ of PBMC and thymocytes were positive for 3A3-antigen and 4B3-antigen when analysed by immunofluorescence. The staining intensity for the 3A3-antigen was very high, more than ten times stronger than that for the 4B3-antigen, both observed by immunofluorescence and on cytospins.

The patterns obtained by immunoenzyme staining of PBMC with mAbs 1B2, 3A3 and 4B3 were quite different from each other. MAb 1B2 stained the cytoplasm homogeneously (figure $4 \mathrm{~A}$ ). MAb $3 \mathrm{~A} 3$, on the other hand, stained strongly patches in the cytoplasm located next to the nucleus, as well as the area next to the nuclear membrane (figure 4B). MAb 4B3 had a granular staining pattern with some of the granules accumulated next to the nuclear membrane (figure 4C). Double immunoenzyme labelling revealed that both $\mathrm{B}$ and $\mathrm{T}$ lymphocytes expressed the 1B2-antigen, 3A3-antigen and 4B3-antigen (data not shown). No cell staining of PBMC was observed with the isotype matched control although the platelets were positive with this $\mathrm{mAb}$ (figure 4D).

\section{Expression on cultured thymic epithelial cells}

Primary cultures of human thymic epithelial cells, obtained from tissue explants, grown in slide flasks, were analysed for expression of the molecules recognised by the new monoclonal antibodies (table I, figure 5). All cells expressed the 3A3-antigen and 4B3-antigen, whereas the majority of the cells expressed the 1B2-antigen. As can be seen in figure 5 the expression was predominantly internal, although the staining pattern did vary for the different mAbs. MAbs $1 \mathrm{~B} 2$ and $3 \mathrm{~A} 3$ both stained all the cytoplasm, where 1B2-antigen was expressed weakly, but quite homogeneously within the cells (figure $5 \mathrm{~A}$ ) compared to 3A3-antigen which was expressed strongly in patches (figure 5B). Expression of 4B3-antigen clearly had a granular pattern with the granules accumulating next to the nucleus (figure 5C). No staining was observed with the isotype matched antibody $\mathrm{mAb}$ 8D4 (figure 5D). For comparison, mouse thymic epithelial cells cultured in slide flasks were also stained with the new monoclonal antibodies (figure 6). Interestingly, the same staining pattern was obtained as with the human thymic epithelial cells.

\section{Regulation of Expression of the Molecules Recognised by the new Monoclonal Antibodies}

\section{By mitogens on PBMC}

PBMC from three healthy individuals were cultured in the presence of medium alone, PHA, Con A, PWM or PMA plus ionomycin. The cells were collected at different time points (4, 24, 48 and 72 hours), fixed and stained in the presence of $0.1 \%$ saponin with mAbs 1B2, 3A3 and 4B3 (figure 7) and with antibodies against CD3, CD20, CD23 and CD25 for comparison (data not shown).

Only PHA upregulated expression of CD3, whereas PHA, PWM and PMA plus ionomycin caused an upregulation in CD23 expression. All the mitogens used caused an upregulation in CD25 expression.

The percentage of PBMC expressing 1B2-antigen declined with increased time in culture (from 32 to $8 \%$ ) and this decline was not affected by Con $\mathrm{A}$ or PWM. On the other hand, PHA and PMA plus ionomycin caused an increase in percentage of positive cells (from 32 to $53 \%$ for PHA and from 32 to $45 \%$ for PMA plus ionomycin). However, this was only observed after 48 hours, with values already back to baseline levels after 72 hours.

Expression of 3A3-antigen and 4B3-antigen decreased even more rapidly with increased time in culture than that observed for 1B2-antigen (from 86 to $41 \%$ and 84 to $26 \%$ for $3 \mathrm{~A} 3$-antigen and $4 \mathrm{~B} 3$-antigen, respectively). This decline in the percentage of positive wells was, though, not observed when cells were cultured in the presence of PHA. 

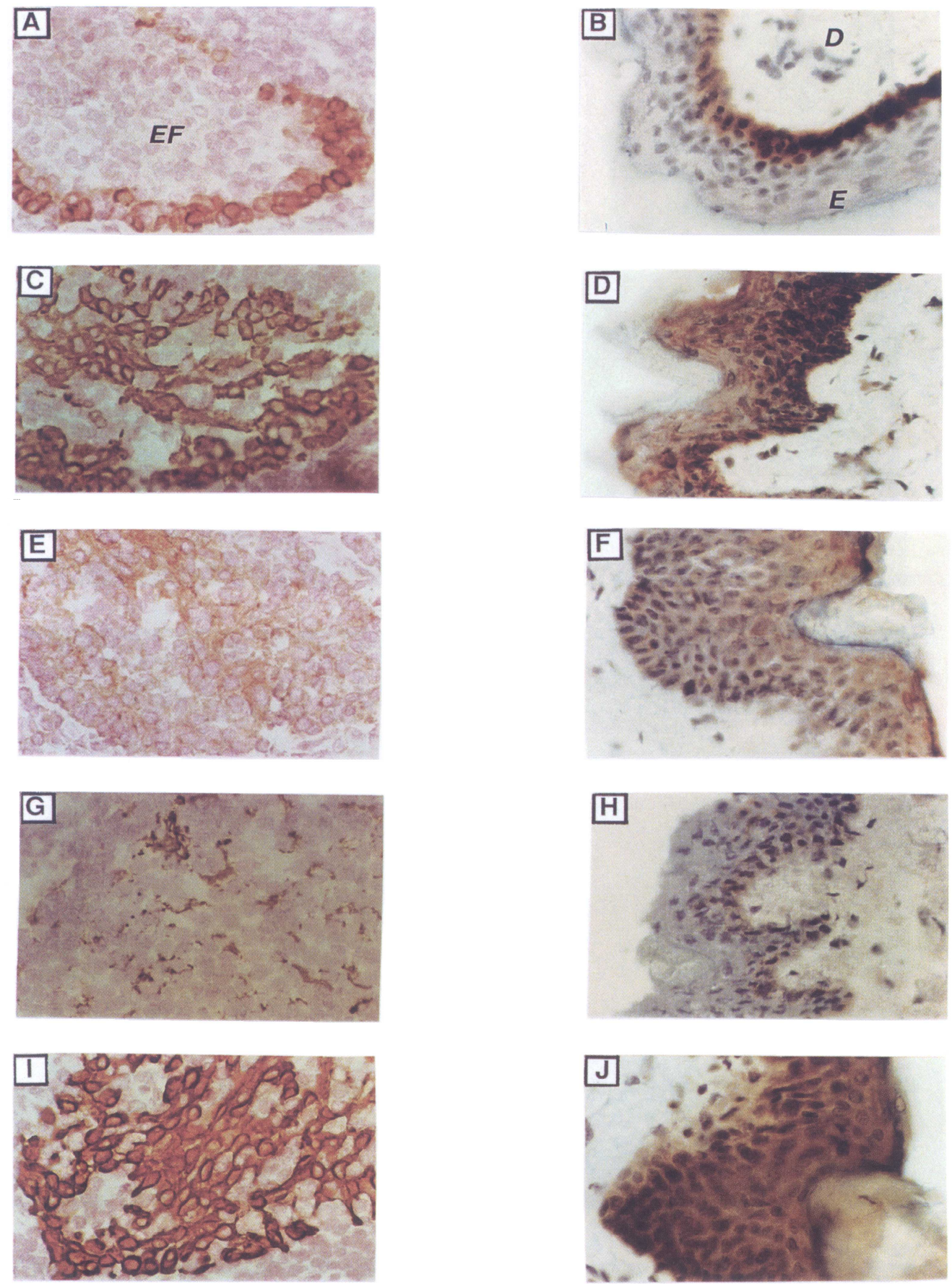

FIGURE 2 Human tonsil (A, C, E, G, I) and skin (B, D, F, H, J) sections immunoperoxidase stained with: mAb 1B2 which labels the basal layer of epidermis on skin and of epithelial folds on tonsil (A, B); mAb 3A3 which labels all epithelial cells (C, D); mAb 4B3 which labels the upper layer of epidermis and the epithelial folds (E, F); mAb 8D4, an isotype matched control, which does not label the epithelium (G, $\mathrm{H}$ ); or anti-cytokeratin 19 antibody which labels all epithelial cells (I, J). A background staining was observed for mAb 8D4 on basal cells in the epidermis which did not exceed staining observed for second antibody alone and blood vessels are labelled with this mAb in the tonsil. Magnification $\times 380$. E, epidermis; D, dermis, EF, epithelial folds (See Color Plate II at the back of this issue) 
TABLE II Influence of cytokines on expression of 1B2-antigen, 3A3-antigen and 4B3-antigen on cultured thymic epithelial cells

\begin{tabular}{lccccc}
\hline & Medium & $I L-2$ & $I L-4$ & $I L-13$ & $I F N-\gamma$ \\
\hline 1B2-antigen & $+/-$ & no change & $\uparrow$ & $\uparrow \uparrow$ & no change \\
3A3-antigen & ++ & no change & $\uparrow$ & no change & $\uparrow$ \\
4B3-antigen & ++ & $\uparrow \uparrow$ & no change & no change & $\uparrow$ \\
\hline
\end{tabular}

negative; +/-, some cells positive; +, all cells positive with medium staining intensity; ++, all cells positive with strong staining intensity;

$\uparrow$, upregulation of expression; $\uparrow \uparrow$, strong upregulation of expression.

\section{By cytokines on cultured thymic epithelial cells}

Thymic epithelial cells were cultured in slide flasks in the presence of medium alone, IL-2, IL-4, IL-13 or IFN- $\gamma$. Then the cells were stained with mAbs 1B2, $3 \mathrm{~A} 3$ and $4 \mathrm{~B} 3$ and with $\mathrm{mAb} 8 \mathrm{D} 4$ as an isotype specific control, and the expression of the 1B2-, 3A3and 4B3-antigens analysed by immunoperoxidase staining (table II, figure 8). IL-2 and, to a lesser extent, IFN- $\gamma$ caused an increase in staining intensity of the 4B3-antigen, whereas IL-13 and, to a lesser degree, IL-4 caused an increase in staining intensity of the 1B2-antigen. Furthermore, IFN- $\gamma$ and IL-4 caused an increase in staining intensity of 3A3-antigen.

\section{DISCUSSION}

Immunisation with purified gp200-MR6 was very successful. Already 10 days after the second immunisation, the sera from the mice contained large quantities of MR6-like antibodies (effective in immunohistochemical staining at a dilution of 1/4000). In order to allow class switching and affinity maturation to occur, the mice were immunised twice more, at intervals of at least 2 weeks.

All fusions resulted in production of hybridoma cells producing MR6-like antibodies. Unfortunately, these hybridoma cells always died, usually at the first cloning stage when cells started to proliferate in the small wells in the 96 well plates. It can be suggested that in the small wells the antibodies were present at high concentration and somehow toxic for the cells. Since B cells use IL-4 as a growth factor it is possible that antibodies which cross-react with the murine gp200-MR6 molecule (i.e. autoreactive) were block- ing cell growth. Thus, it seem likely that conventional hybridoma technology is unlikely to yield more MR6-like antibodies. This has, however, been successful using phage-display technology (Palmer et al., 1999).

Surprisingly, each fusion produced hybridoma cells secreting antibodies with specificities other than those that were MR6-like. Amongst the specificities detected were staining of all or some epithelial cells, of thymocytes, of thymocytes and some/all epithelial cells, of blood vessels, of macrophages and of intercellular tissue. This diversity in staining pattern was very surprising, since purified gp200-MR6 had been used for immunisation. One explanation could be that the gp200-MR6 was indeed not completely pure. This is unlikely, since eluates run on SDS/PAGE and stained with Coomassie blue did not reveal any additional bands other than those recognised by $\mathrm{mAb}$ MR6. Another explanation is that the polyclonal activation, caused by the adjuvant, stimulated autoreactive B cells, producing antibodies that cross-reacted with human molecules. During evolution, many important proteins have conserved genes that can be found in unrelated species. Rabbit antibodies against human cytokeratins or laminins can, for example, be used to stain mouse cytokeratins or laminins (personal observation). Previous studies, confirming this suggestion, have shown that supernatants of hybridomas, obtained from normal, germ free, nude (athymic) and neonatal mice, produced antibodies reactive with intracellular structures in mouse, rat and human fibroblasts or autologous macromolecules, such as actin, tubulin, myosin and dsDNA) (Underwood et al., 1985; Lymberi et al., 1989). Interestingly, these auto-reactive hybridomas could be obtained from both primed and unprimed mice. 


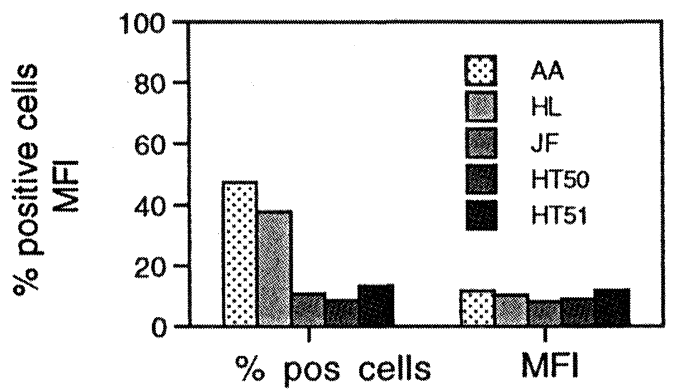

$1 B 2$

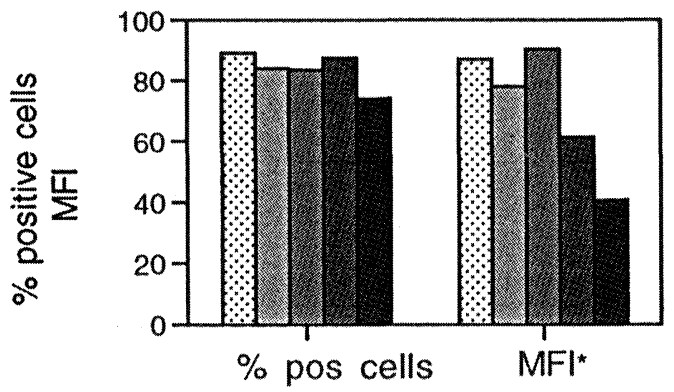

3A3

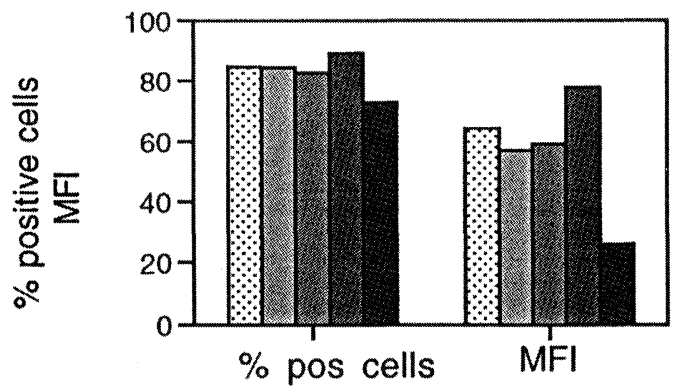

4B3

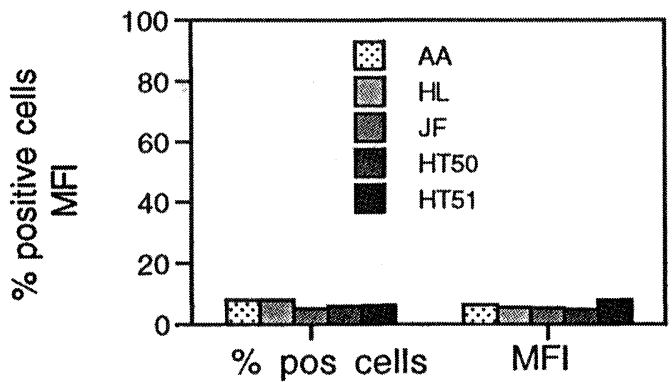

8D4

FIGURE 3 Intracellular expression of molecules recognised by mAbs 1B2, 3A3 and 4B3 and an isotype matched control (mAb 8D4) on PBMC (AA, HL, JF) and thymocytes (HT50, HT51), analysed by immunofluorescence and flow cytometry on fixed and saponin treated cells, with results expressed as percentage positive cells or mean fluorescence intensity (MFI). * indicates that actual MFI is 10 times higher than levels shown

Molecular mimicry could also be an explanation for the occurrence of the non MR6-like antibodies. This has been observed for antibodies against the streptococcal A carbohydrate, terminal $O$-linked $\mathrm{N}$-acetyl- $\beta$-D-glucosamine (GlcNAc), produced during streptococcal infection, which cross-react with 

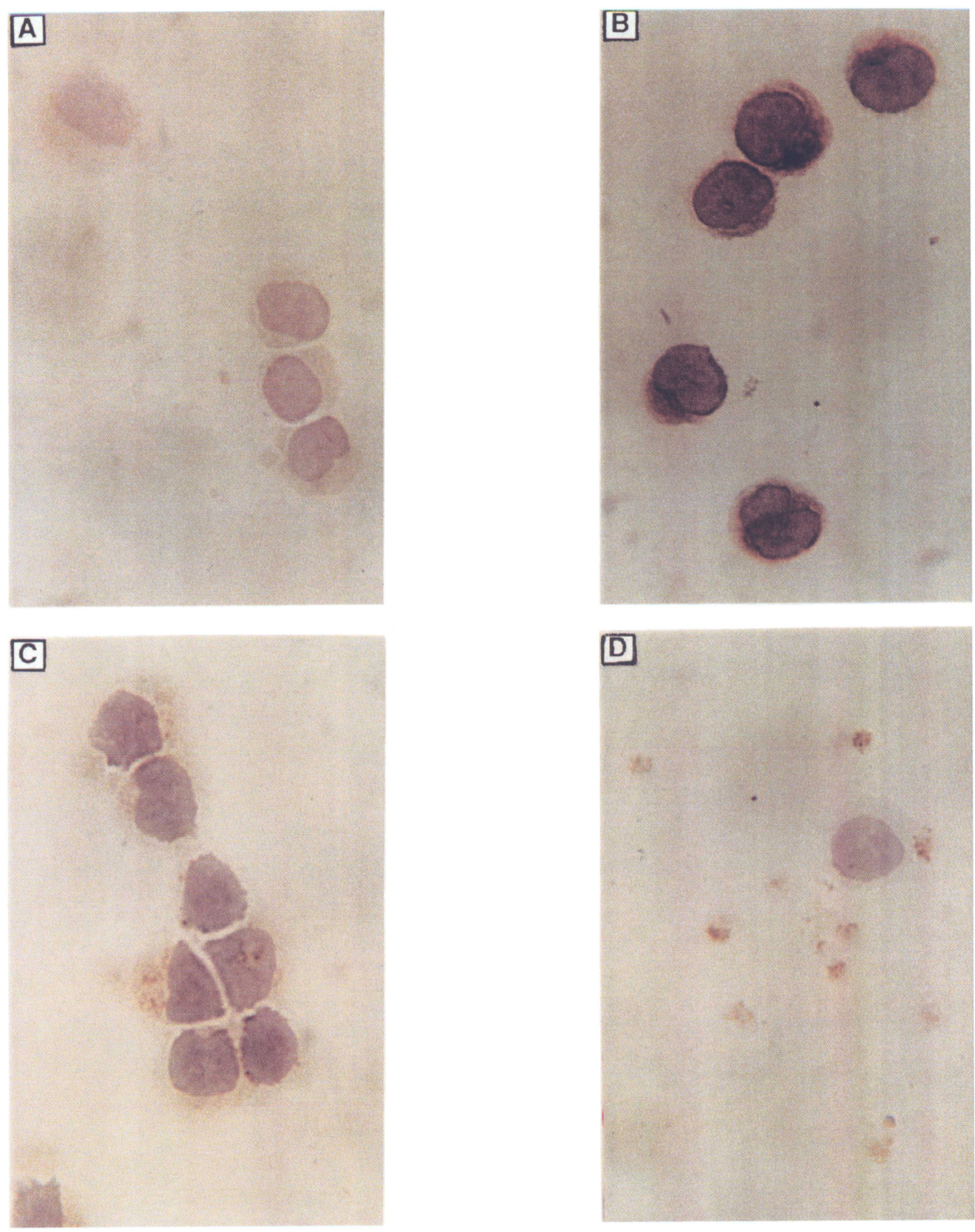

FIGURE 4 Cytospins of PBMC immunoperoxidase stained with: mAb 1B2 which labels the cytoplasm weakly (A); mAb 3A3 which stains patches in the cytoplasm strongly and also around the nuclear membrane (B); mAb 4B3 which has granular staining pattern within the cytoplasm (C); and an isotype matched control (mAb 8D4) which does not stain the PBMC but stains the platelets (D). Magnification $\times 1338$ (See Color Plate III at the back of this issue)

epithelial cells in skin, thymus, tonsil and intestine (Sharif et al., 1990). It was also shown that human
anti-GlcNAc antibodies cross-react with cytokeratin from human skin (Shikman and Cunningham, 1994). 
Furthermore, mouse anti-streptococcal antibodies expressing anti-GlcNAc activity were found to react with several cytoskeletal proteins, such as actin, vimentin, myosin and cytokeratin (Shikman et al., 1993). Further studies with monoclonal antibodies against GlcNAc or to cytokeratin (Shikman and Cunningham, 1994, Shikman et al., 1994) suggested that certain peptides, containing $O$-linked GlcNAc, could induce an anti-carbohydrate antibody response in vivo. All the new monoclonal antibodies were IgM, suggesting that they might be against carbohydrates. An internal infection amongst the mice could provoke such an immune response. On the other hand, although gp200-MR6 only contains $N$-linked sugars it could act as the non-cytokeratin molecules containing $O$-linked GlcNAc described by Shikman and Cunningham (1994) which induced antibodies against cytokeratin in BALB/c mice.

Three hybridomas secreting non MR6-like antibodies were selected for further studies. MAbs 1B2, 3A3 and 4B3 stained epithelial cells in human thymus, tonsil and skin. MAb 3A3 stained all epithelial cells in thymus, epidermis and tonsil, a staining pattern also observed for cytokeratins (personal observations). MAb 1B2 stained only some medullary epithelial cells in the thymus and the basal layer of the epidermis of the skin and the basal layer of the epithelial folds of the tonsils. MAb 4B3, on the other hand, stained Hassall's corpuscles in the thymus and the upper layer of the epidermis (squamous epithelium) and the outer cell layer of the epithelial folds within the tonsil. Many monoclonal antibodies against Hassall's corpuscles have been produced using crude thymus or peptides based on the gene sequence of the IL-4 receptor as immunogens and the majority of these antibodies were IgM and likely to be against carbohydrates (de Maagd et al., 1985; Mat, 1992; Imami et al., 1997). However, an antibody recognising only some medullary thymic epithelial cells adds further proof for the existence of subpopulations of medullary epithelial cells (van der Wijngaert et al., 1984; Farr et al., 1993). The role of the medullary epithelium in thymocyte development is still unknown. It has been shown that some medullary thymocytes go through cell division before leaving the thymus (Ernst et al., 1995), suggesting that the medullary stromal cells provide the necessary proliferative signals. These signals might be provided by some of the medullary epithelial cells. Furthermore, it has been shown that medullary epithelial cells are able to induce negative selection of thymocytes (Volkmann et al., 1997).

By staining tissue sections it was observed that mAbs $3 A 3$ and 4B3 also stained thymocytes and lymphocytes, as seen on thymus and tonsil for mAb $4 \mathrm{~B} 3$ and on thymus for mAb $3 \mathrm{~A} 3$. This observation was confirmed by staining thymocytes and PBMC in suspension. Surprisingly, mAb 1B2 was also found to stain thymocytes and PBMC, where $10-47 \%$ of the cells from different individuals were positive when analysed by immunofluorescence staining and flow cytometry. Expression of 1B2-antigen was found to be influenced by cytokines. Therefore, the variation of percentage of 1B2-antigen positive cells from different individuals may reflect different cytokine regulation. Double labelling studies revealed that all these antibodies stained both $\mathrm{B}$ and $\mathrm{T}$ cells. This observation adds 1B2-antigen, 3A3-antigen and 4B3-antigen to the group of molecules which are expressed on both lymphoid and non-lymphoid cells and makes them possible candidates participating in the cell-cell cross-talk occurring in the thymus, as suggested by Ritter and Boyd (1993). Several such molecules (e.g. gp200-MR6 and MTS 12, 32, 33, 35 and 37) have been investigated in further details (Larché et al., 1988a; Tucek et al., 1992; Al-Tubuly et al., 1996).

All three molecules recognised by mAbs 1B2, 3A3 and $4 \mathrm{~B} 3$ are expressed predominantly internally. However, mAb $3 \mathrm{~A} 3$ stained the surface of the squamous epithelium in the skin, as well as the cytoplasm. These are the most differentiated epithelial cells in the skin, suggesting that $3 \mathrm{~A} 3$-antigen is transported out on the surface when the epithelial cells reach a more mature stage. The staining patterns on PBMC and cultured epithelial cells obtained by the different mAbs varied considerably. MAb 1B2 stained the cytoplasm quite homogeneously, mAb $3 \mathrm{~A} 3$ stained patches in the cytoplasm very strongly as well as the area around/at the nuclear membrane and mAb 4B3 stained granules within the cytoplasm. The molecules may be part of the intracellular structure; however, the 

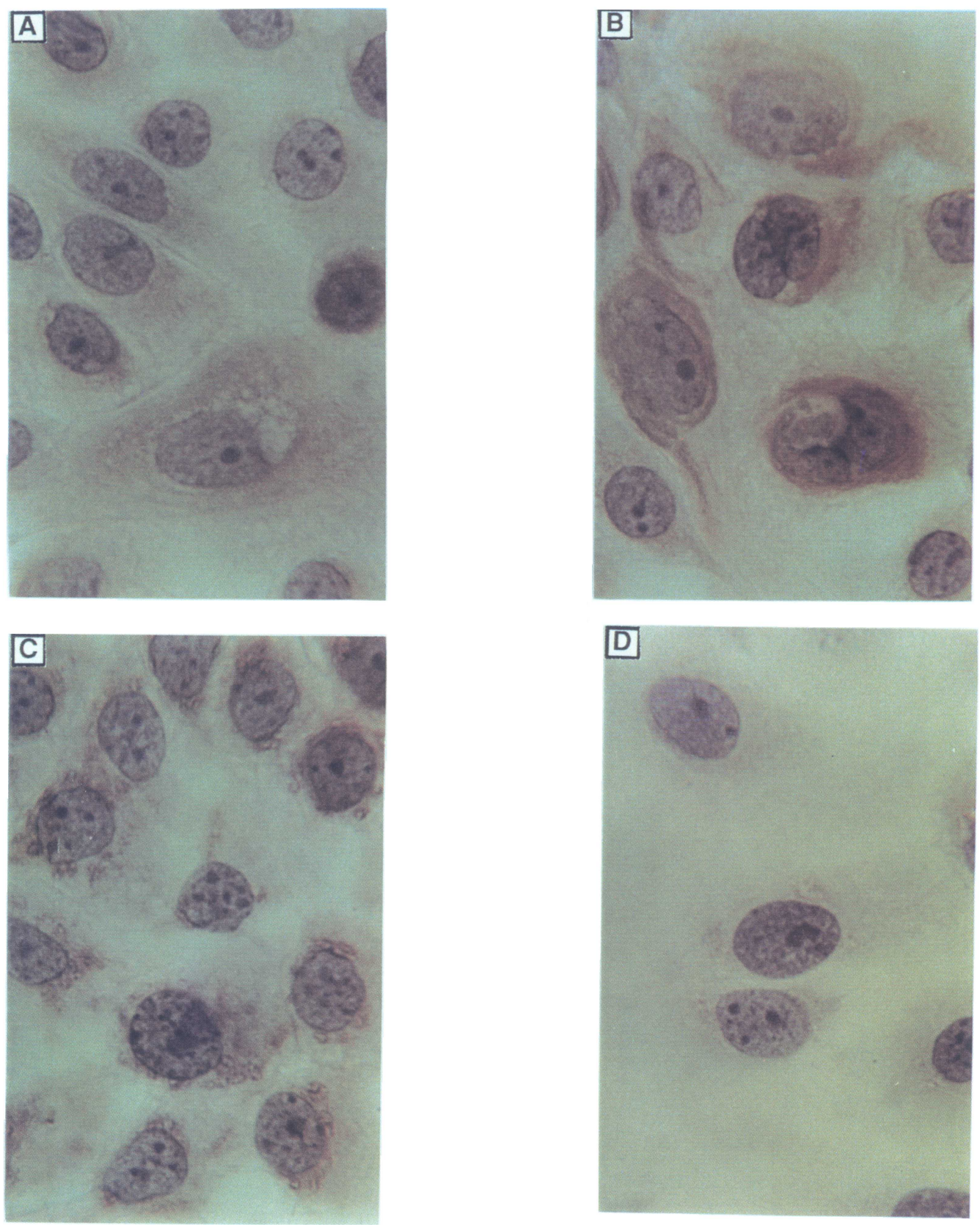

FIGURE 5 Human thymic epithelial cells cultured on slides and immunoperoxidase stained with: mAb $1 \mathrm{~B} 2$ which labels the cytoplasm weakly but homogeneously (A); mAb 3A3 which stains patches in the cytoplasm very strongly (B); mAb 4B3 which has granular staining pattern (C); and an isotype matched control (mAb 8D4) which does not stain the epithelial cells (D). Magnification x 1338 (See Color Plate IV at the back of this issue)

dense staining patches observed for $\mathrm{mAb} 3 \mathrm{~A} 3$ near to the nuclei of the epithelial cells and PBMC, as well as the granular staining observed for mAb 4B3, suggest that the molecules they recognise could be localised 

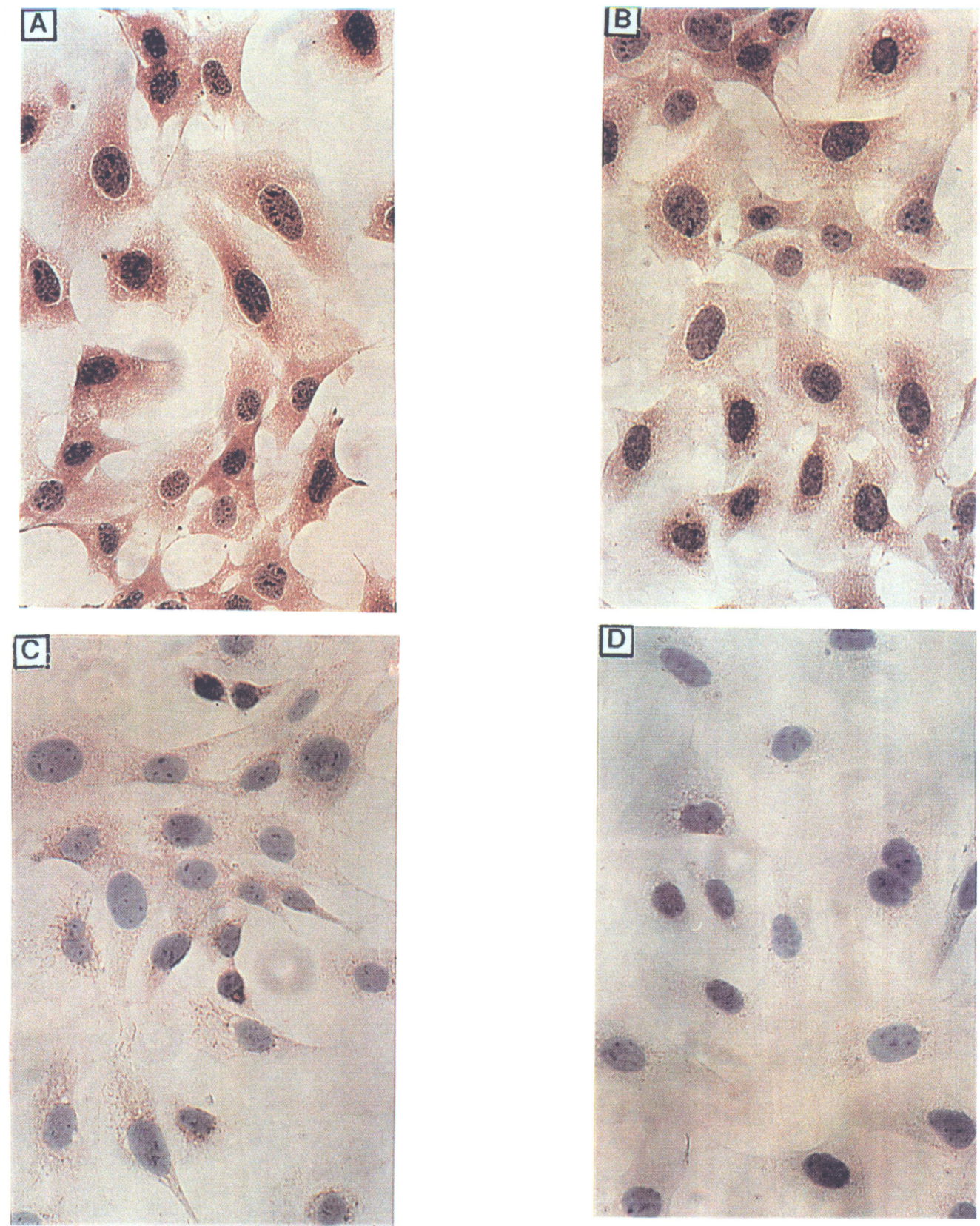

FIGURE 6 Mouse thymic epithelial cells (F1) cultured on slides and immunoperoxidase stained with: mAb 1B2 which labels the cytoplasm homogeneously (A); mAb 3A3 which stains the cytoplasm (B); mAb 4B3 which has granular staining pattern (C); and an isotype matched control (mAb 8D4) (D). Magnification x 540 (See Color Plate V at the back of this issue)

within intracellular compartments and destined for secretion.

Expression of several molecules shared by lymphoid and stromal cells, such as gp200-MR6, LFA-1 and ICAM-1, has been shown to be upregulated during activation (Larché et al., 1988a; de Rose et al., 1994; Marker et al., 1995; Freysdottir and Ritter, manuscript in preparation). Since 1B2-antigen, 


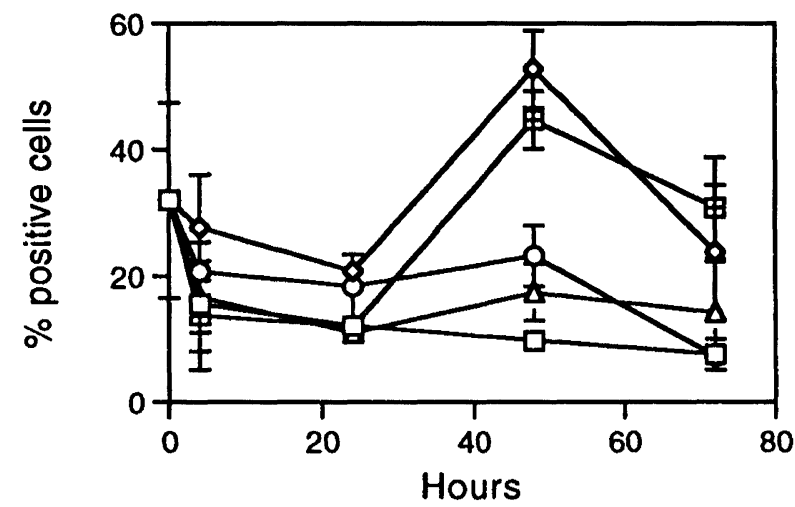

\section{B2-ag}

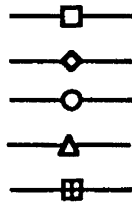

Medium

PHA

Con A

PWM

PMA+ionomycin

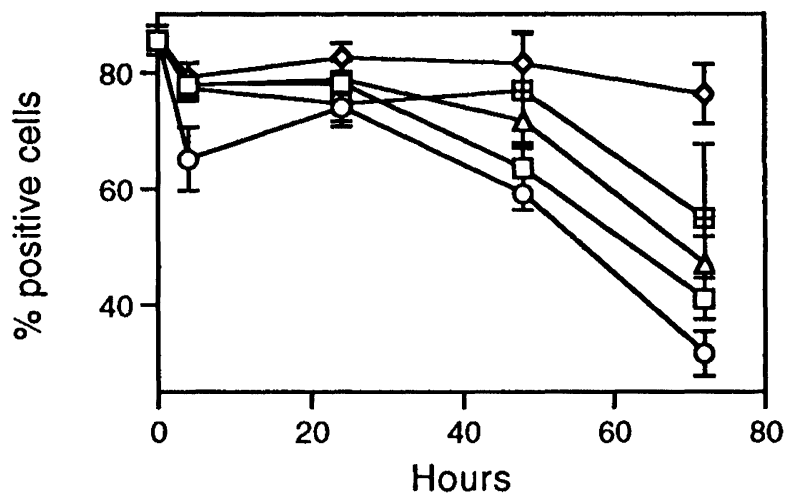

3A3-ag

- Medium

$\longrightarrow$ PHA

$-\operatorname{Con} A$

$\triangle$ PWM

巴 PMAtionomycin

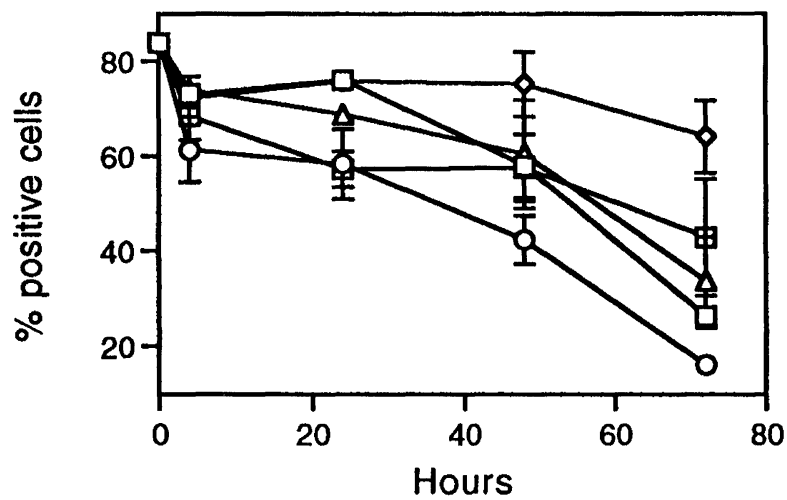

4B3-ag

-

$\longrightarrow$ PHA

$\longrightarrow$ Con A

$\triangle$ PWM

田- PMA+ionomycin

FIGURE 7 Influence of mitogens on expression of 1B2-antigen, 3A3-antigen and 4B3-antigen in/on PBMC from three individuals, analysed after fixation by immunofluorescence and flow cytometry, with results expressed as percentage positive cells (mean \pm standard deviation)

3A3-antigen and 4B3-antigen are all expressed on lymphocytes and thymic epithelium, we analysed whether mitogens or cytokines would affect their expression on PBMC or cultured thymic epithelial cells, respectively.
The expression of all the three antigens recognised by $\mathrm{mAbs} 1 \mathrm{~B} 2,3 \mathrm{~A} 3$ and $4 \mathrm{~B} 3$ in/on PBMC declined with increased time in control cultures. The polyclonal $\mathrm{T}$ cell activator, PHA, was the only mitogenic compound that could inhibit the decline in expression 
of 3A3-antigen and 4B3-antigen. On the other hand, PHA and PMA plus ionomycin and, to a lesser extent, Con A and PWM caused an increase in expression of 1B2-antigen, observed only after 48 hours in culture. When the cells were analysed 24 hours later this increase was barely detectable. PHA and Con A only activate $\mathrm{T}$ cells, most likely by binding to component chains of the TCR/CD3 complex (Kanellopoulos et al., 1985). Therefore, expression of 1B2-antigen, 3A3-antigen and 4B3-antigen on $\mathrm{T}$ cells must be affected by the activation stage. PMA plus ionomycin can mimic some of the events that are associated with TCR stimulation (Truneh et al., 1985) and cross-linking of membrane bound Ig (Gold et al., 1991) and PWM does also activate both $\mathrm{T}$ and $\mathrm{B}$ cells. Therefore, it cannot be concluded whether mitogens also affect expression of 1B2-antigen on B cells as well as on $\mathrm{T}$ cells.

All cultured human thymic epithelial cells express 3A3-antigen and 4B3-antigen and the majority of the cells express 1B2-antigen but very weakly. Increased staining intensity was observed for 1B2-antigen if the cells were treated with IL-4 or IL-13. It has been proposed that IL-4 and IL-13 induce maturation of cultured thymic epithelial cells (Freysdottir and Ritter, manuscript in preparation). The findings reported here would, therefore, suggest that expression of the molecules recognised by mAb $1 \mathrm{~B} 2$ is influenced by the maturation stage of the epithelial cells, with upregulation in expression with increased maturation. In contrast, expression of the 4B3-antigen was increased when cells were cultured in the presence of IL-2 or IFN- $\gamma$, while treatment with either IL-4 or IFN- $\gamma$ caused a slight upregulation of 3A3-antigen expression, showing that both Th1 and Th2 cytokines could influence the 3A3-antigen expression. These results indicate that expression of the three molecules recognised by mAbs $1 B 2,3 A 3$ and $4 B 3$ is differentially regulated by cytokines produced within the thymus, raising the possibility that thymocyte subpopulations might control development of distinct microenvironmental nichies.

In summary, we have identified three novel molecules that are expressed in human thymus by both developing thymocytes and their epithelial microen- vironment. This shared distribution and the regulation of their expression by $\mathrm{T}$ cell-derived cytokines suggest that these molecules may be important in intrathymic cross-talk. Future studies will focus on their structure and function.

\section{MATERIALS AND METHODS}

\section{Purification of Gp200-MR6}

Gp200-MR6 was purified from lysates of human thymus by affinity chromotography using an Immunopure ${ }^{\circledR}$ $\mathrm{Ag} / \mathrm{Ab}$ Immobilization Kit (Pierce \& Warriner, Chester, England). The mAb MR6 $(4.6 \mathrm{mg} / \mathrm{ml}$ in $50 \mathrm{mM}$ sodium acetate buffer, $\mathrm{pH}$ 5.5) was immobilised to the agarose beads according to the manufacturer's protocol. The MR6-agarose was finally divided into $500 \mu \mathrm{l}$ aliquots.

Frozen sections of human thymic tissue (obtained from children aged 5 days to 8 years that were undergoing cardiac surgery at the Great Ormond Street Hospital for Sick Children and Royal Brompton Hospital, London) were solubilised and used as the source of gp200-MR6, as previously described by Al-Tubuly et al. (1996). Approximately 100 sections, $18 \mu \mathrm{m}$ thick, were cut in a cryostat, placed into an ice cold tube and then solubilised in $1.2 \mathrm{ml}$ of lysis buffer $(10$ $\mathrm{mM}$ Tris-HCl, $\mathrm{pH} 7.2$, containing $1 \%$ Nonidet P-40 and $1 \mathrm{mM}$ phenylmethyl-sulfonyl fluoride) for 15 minutes on ice. The tubes were centrifuged at 10,000 rpm at $4{ }^{\circ} \mathrm{C}$ for 15 minutes. The supernatant, containing the solubilised gp200-MR6, was collected and either used immediately or stored at $-20^{\circ} \mathrm{C}$.

The purification of gp200-MR6 was performed at $4^{\circ} \mathrm{C} .1 \mathrm{ml}$ of thymic lysate was added into $500 \mu \mathrm{l}$ of MR6-agarose. The agarose was resuspended and the tubes placed on a rotator for 40 minutes. The tubes were then spun in a microfuge for several seconds and the thymic lysate removed carefully. This was repeated four times with fresh thymic lysate each time. Then the agarose was washed six times with $1 \mathrm{ml}$ PBS for 5 minutes. Elution of gp200-MR6 was performed by mixing $500 \mu \mathrm{l}$ of $0.1 \mathrm{M}$ glycine buffer, 

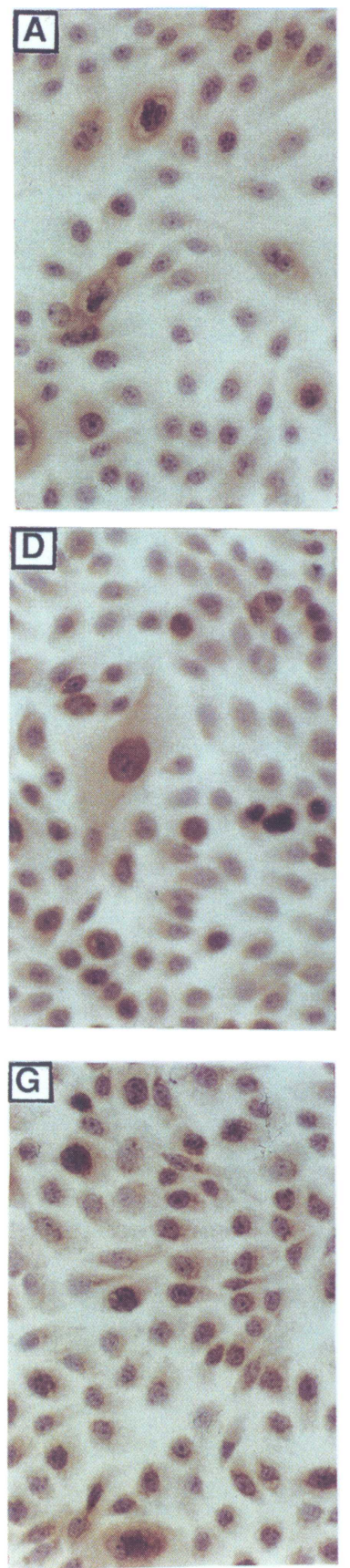
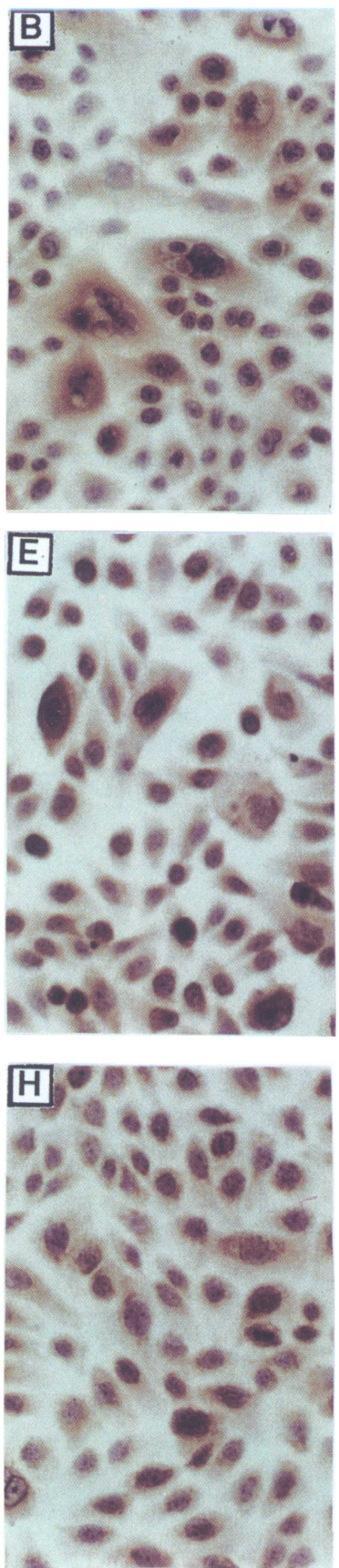
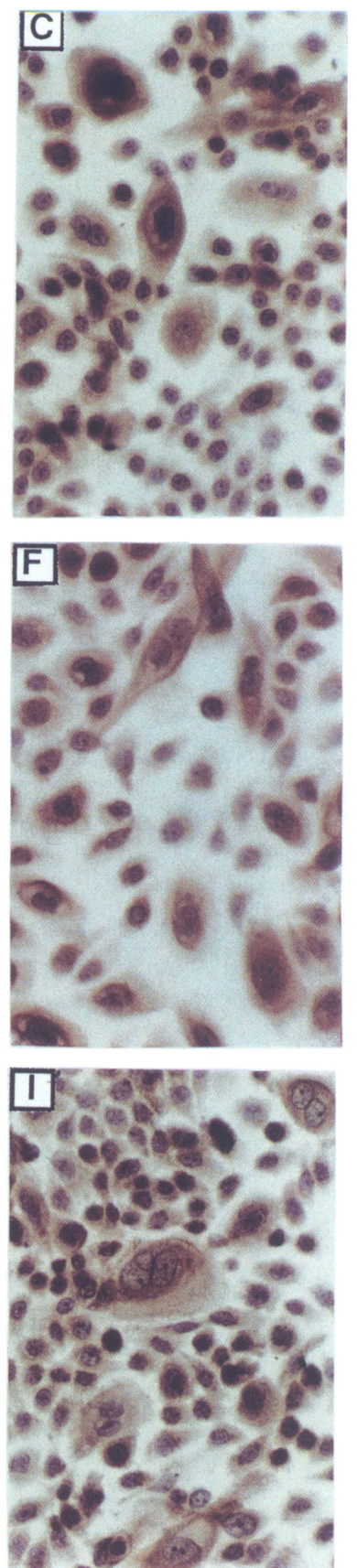

FIGURE 8 Thymic epithelial cells cultured on slides in the presence of medium alone (a, d, g), IL-2 (h), IL-4 (b, e), IL-13 (c) or IFN- $\gamma$ (f, i), immunoperoxidase stained with mabs 1B2 $(\mathrm{a}, \mathrm{b}, \mathrm{c}), 3 \mathrm{~A} 3(\mathrm{~d}, \mathrm{e}, \mathrm{f})$ or 4B3 $(\mathrm{g}, \mathrm{h}, \mathrm{i})$. Expression of 1B2 was upregulated by IL-4 and IFN- $\gamma$ and expression of 4B3 was slightly upregulated by IL-2 and IFN- $\gamma$. Magnification x 380 (See Color Plate VI at the back of this issue)

$\mathrm{pH} 2.8$, with the agarose for 1 minute, spinning the tubes for few seconds and removing the eluate care- fully. This was repeated five times. The eluates were transferred into tubes already containing $30 \mu \mathrm{l}$ of 0.1 
$\mathrm{M}$ Tris- $\mathrm{HCl}, \mathrm{pH} 9.4$, in order to adjust the $\mathrm{pH}$ to approximately 7.5 .

The presence of gp200-MR6 in the eluates was confirmed by Western blotting. Membranes were stained with mAb MR6 or second antibody alone which should detect any contamination of mAb MR6 in the eluates. The amount of gp200-MR6 in the eluates was estimated by measuring protein concentration by a microtiter plate version of the Lowry method.

\section{Production of Hybridoma Cells}

BALB/c female mice between 6 and 8 weeks old were immunised ip with $200 \mu \mathrm{l}$ of purified human gp200-MR6 (approximately $20 \mu \mathrm{g}$ ) mixed with 100 $\mu 1$ of complete Freund's adjuvant. The mice were boosted twice at three to five week intervals with purified gp200-MR6 mixed with incomplete Freund's adjuvant. The final injection was with the purified gp200-MR6 alone, four days before a fusion was performed. During fusion the myeloma cells, NSO, were added to the splenocytes at a ratio of one NSO myeloma cell per 6 to 10 splenocytes (a yield of 1.5 to 2.0 $\times 10^{8}$ splenocytes was usually obtained). After the fusion the cells were plated out into 24 well plates at a concentration of 1 to $2 \times 10^{5}$ cells per well. Supernatants from wells that contained hybridoma cell clones were screened for presence of MR6-like antibodies by immunoperoxidase staining of thymic sections. Positive hybridoma cells were subsequently cloned three times by limiting dilutions to ensure single clones. Antibodies were isotyped and all shown to be IgM (Isotyping kit, Serotec, Oxford, England).

\section{Analysis of the Molecules Recognised by the new Monoclonal Antibodies}

Sections prepared from human thymus, tonsils and skin, cultured human TEC obtained from explants of human thymic tissues (Freysdottir and Ritter, manuscript in preparation), cultured mouse TEC (F1), and cytospins of human PBMC were immunoperoxidase stained with the hybridoma supernatants. For compar- ison and positive control, the sections and cultured human TEC were also stained with antibody against cytokeratin 19 (clone K4.62; Sigma, Poole, England) and an isotype matched control antibody (mAb 8D4, labels endothelium and platelets only was added as negative control). The cytospins were double stained by the immunoperoxidase technique with hybridoma supernatants and then by the alkaline phosphatase technique with mAbs (all from Dako, High Wycombe, England) against CD3 (clone T3-4B5) or against CD19 (clone HD37), CD20 (clone B-Lyl) and CD22 (clone 4KB128). Secondary antibodies were rabbit-anti mouse Ig conjugated to either peroxidase or alkaline phosphatase (Dako).

Cell suspensions of human PBMC and thymocytes were stained by indirect immunofluoroscence with hybridoma supernatants. MAb 8D4 was included as an isotype matched antibody control. Rabbit anti-mouse Ig labelled with fluorescein isothiocyanate (Dako) was used as secondary antibody. After staining the cells were fixed in $1 \%$ paraformaldehyde and analysed by flow cytometry (Epics XL, Coulter, Hileah, USA). In order to analyse intracellular molecules, cells were fixed with $1 \%$ paraformaldehyde for 10 minutes on ice prior to staining and $0.1 \%$ saponin was included in all washing and incubation steps. Results were expressed as percentage positive cells, compared to cells stained with an isotype matched control, or mean fluorescence intensity (MFI).

\section{Regulation of the Expression of the Molecules Recognised by the new Monoclonal Antibodies}

Freshly isolated PBMC from three healthy individuals were incubated at $2 \times 10^{6}$ cells per well in a 24 well plate. The cells were cultured in medium alone (RPMI medium supplemented with $10 \%$ foetal calf serum) or in the presence of mitogens (Sigma), phytohemagglutinin (PHA), used at $2 \mu \mathrm{g} / \mathrm{ml}$, concanavalin A (Con A), used at $25 \mu \mathrm{g} / \mathrm{ml}$, pokeweed mitogen (PWM), used at $2.5 \mu \mathrm{g} / \mathrm{ml}$, and phorbol 12-myristate 13-acetate (PMA), used at $10 \mathrm{ng} / \mathrm{ml}$ together with 1 $\mu \mathrm{g} / \mathrm{ml}$ of the calcium ionophore ionomycin. The concentrations used were all within the range recommended by the manufacturer. Cells were harvested 
after 4, 24, 48 and 72 hours and analysed by immunofluorescence and flow cytometry. Approximately $2 \times$ $10^{5}$ cells were incubated with mAbs (Dako) against CD3, CD23 (clone MHM6) or CD25 (clone ACT-1) for analysing surface expression or with hybridoma supernatants for internal and/or surface expression.

Thymic epithelial cells, growing in slide flasks, were cultured for 48 hours in the presence or absence of IL-2 $(20 \mathrm{U} / \mathrm{ml}$, Boehringer Mannheim, Lewes, England), IL-4 (50 U/ml, Genzyme Diagnostics, Kings Hill, England), IL-13 (15 ng/ml, Pepro Tech, Rocky Hill, NJ, USA) or IFN- $\gamma(100 \mathrm{U} / \mathrm{ml}$, Genzyme). The cells were then stained by the indirect immunoperoxidase technique using hybridoma supernatants and analysed using light microscopy by two independent observers. The intensity of staining of untreated and treated cells was compared. Results were given as no change (no change in staining intensity), upregulation (increase in staining intensity) or downregulation (decrease in staining intensity).

\section{Acknowledgements}

This work was supported by NATO Fellowship, Ida MacLean Fellowship (International Federation of University Women), Helga Jonsdottir and Sigurlidi Kristjansson's Memorial Fund, Bergthora Magnusdottir and Jakob Bjarnason's Memorial Fund, Theodor Johnson's Memorial Fund, and Islandsbanki's Studentline.

\section{References}

Al-Tubuly, A.A., Luqmani, Y.A., Shousha, S., Melcher, D. and Ritter, M.A. (1996) Downregulation of the IL-4 receptor-associated molecule gp200-MR6 in invasive carcinoma and differential expression in benign hyperplasia of the breast. $\mathrm{Br}$. J. Cancer 74: 1005-1011.

Al-Tubuly, A.A., Spijker, R., Pignatelli, M., Kirkland, S. and Ritter, M.A. Inhibition of proliferation and enhancement of differentiation of human colorectal cell lines by MAb MR6 and interleukin-4. Int. J. Cancer 71: 605-611.

Boyd, R.L., Tucek, C.L., Godfrey, D.I., Izon, D.J., Wilson, T.J., Davidson, N.J., Bean, A.G.D., Ladyman, H.M., Ritter, M.A. and Hugo, P. (1993) The thymic microenvironment. Immunol. Today 14: 445-459.

de Maagd, R.A., Mackenzie, W.A., Schuurman, H.-J., Ritter, M.A., Price, K.M., Broekhuizen, R. and Kater, L. (1985) The human thymus microenvironment: heterogeneity detected by monoclonal anti-epithelial cell antibodies. Immunology 54: 745754. de Rose, V., Rolla, G., Bucca, C., Ghio, P., Bertoletti, M., Baderna, P. and Pozzi, E. (1994) Intercellular adhesion molecule-1 is upregulated on peripheral blood $\mathrm{T}$ lymphocyte subsets in dual asthmatic responders. J. Clin. Invest. 94: 1840-1845.

Ernst, B., Surh, C.D. and Sprent, J. (1995) Thymic selection and cell division. J. Exp. Med. 182, 961-972.

Farr, A., Nelson, A., Hosier, S. and Kim, A. (1993) A novel cytokine-responsive cells surface glycoprotein defines a subset of medullary thymic epithelium in situ. J. Immunol. 150, 1160-1171.

Gold, M.R., Matsuuchi, L., Kelly, R.B. and DeFranco, A.L. (1991) Tyrosine phosphorylation of components of the B-cell antigen receptors following receptor crosslinking. Proc. Natl. Acad. Sci. USA 88: 3436-3440.

Imami, N., Ladyman, H.M., Vincents, B., Al-Tubuly, A., Freysdottir, J., Sedibane, M.L., Taylor-Fishwick, D.A., Foxwell, B. and Ritter, M.A. (1998) K21-antigen - a molecule shared by the microenvironments of the human thymus and germinal centres. Devel. Immunol. 6: 41-52.

Imami, N., Larché, M. and Ritter, M.A. (1994) Inhibition of alloreactivity by mAb MR6: differential effects on IL-2-and IL-4-producing human T cells. Int. Immunol. 6: 1575-1584.

Kampinga, J., Berges, S., Boyd, R.L., Brekelmans, P., Colic, M., van Ewijk, W., Kendall, M.D., Ladyman, H., Nieuwenhuis, P., Ritter, M.A., Schuurman, H.-J. and Tournefier, A. (1989) Thymic epithelial antibodies: Immunohistological analysis and introduction of nomenclature. Thymus 13: 165-173.

Kanellopoulos, J.M., De Petris, S., Leca, G. and Crumpton, M.J. (1985) The mitogenic lectin from Phaseolus vulgaris does not recognize the T3 antigen of human T lymphocytes. Eur. J. Immunol. 15: 479-486.

Larché, M., Lamb, J.R. and Ritter, M.A. (1988a) A novel T-lymphocyte molecule that may function in the induction of self-tolerance and MHC-restriction within the human thymic microenvironment. Immunology 64: 101-105.

Larché, M., Lamb, J.R., O'Hehir, R.E., Imami-Shita, N., Zanders, E.D., Quint, D.E., Moqbel, R. and Ritter, M.A. (1988b) Functional evidence for a monoclonal antibody that binds to the human IL-4 receptor. Immunology 65: 617-622.

Lymberi, P., Blancher, A., Calvas, P. and Avrameas, S. (1989) Natural autoantibodies in nude and normal outbred (Swiss) and inbred mice (BALB/c) mice. J. Autoimmunity 2: 283-295.

Marker, O., Scheynius, A., Christensen, J.P. and Thomsen, A.R. (1995) Virus-activated T cells regulate expression of adhesion molecules on endothelial cells in sites of infection. J. Neuroimmunol. 62: 35-42.

Mat, I., Larché, M., Melcher, D. and Ritter, M.A. (1990) Tumour-associated upregulation of the IL-4 receptor complex. Br. J. Cancer (suppl) 10: 96-98.

Mat, I. (1992) Analysis of human interleukin 4 receptor-associated molecule (gp200-MR6 molecule) in normal and transformed epithelium. PhD thesis. University of London.

Palmer, D.B., George, A.J.T. and Ritter, M.A. (1997) Selection of antibodies to cell surface determinants on mouse thymic epithelial cells using a phage display library. Immunology 91: 473-478.

Palmer, D.B., Crompton, T., Marandi, M.B., George, A.J.T. and Ritter, M.A. (1999) Intrathymic function of the human cortical epithelial cell surface antigen gp200-MR6: single-chain antibodies to evolutionarily conserved determinants disrupt mouse thymus development. Immunology 96: 236-245.

Ritter, M.A. and Boyd, R.L. (1993) Development in the thymus: it takes two to tango. Immunol. Today 14: 462-469. 
Ritter, M.A. and Crispe, I.N. (1992) The Thymus. (Oxford, IRL Press).

Sharif, M., Rook, G., Wilkinson, L.S., Worrall, J.G. and Edwards, J.C.W. (1990) Terminal N-acetylglucosamine in chronic synovitis. Br. J. Rheumatol. 29: 25-31.

Shikhman, A.R., Greenspan, N.S. and Cunningham, M.W. (1993) A subset of mouse monoclonal antibodies cross-reactive with cytoskeletal proteins and group A streptococcal $\mathbf{M}$ proteins recognizes N-acetyl- $\beta$-D-glucosamine. J. Immunol. 151: 3902-3913.

Shikhman, A.R. and Cunningham, M.W. (1994) Immunological mimicry between $\mathrm{N}$-acetyl- $\beta$-D-glucosamine and cytokeratin peptides. J. Immunol. 152: 4375-4387.

Shikhman, A.R., Greenspan, N.S. and Cunningham, M.W. (1994) Cytokeratin peptide SFGSGFGGGY mimics $\mathrm{N}$-acetyl- $\beta$-D-glucosamine in reaction with antibodies and lectins, and induces in vivo anti-carbohydrate antibody response. J. Immunol. 153: 5593-5606.

Truneh, A., Albert, F., Golstein, P. and Schmitt-Verhulst, A.-M. (1985) Early steps of lymphocyte activation bypassed by syn- ergy between calcium ionophores and phorbol ester. Nature 313: $318-320$.

Tucek, C.L., Godfrey, D.I. and Boyd, R.L. (1992) Five novel antigens illustrate shared antigenicity between mouse thymic stromal cells, thymocytes and peripheral lymphocytes. Int. Immunol. 4: 1021-1030.

Underwood, J.R., Pedersen, J.S., Chalmers, P.J. and Toh, B.H. (1985) Hybrids from normal, germ free, nude and neonatal mice produce monoclonal autoantibodies to eight different intracellular structures. Clin. Exp. Immunol. 60: 417-426.

van der Wijngaert, F.P., Kendall, M.D., Schuurman, H.-J., Rademakers, L.P.H.M. and Kater, L. (1984) Heterogeneity of epithelial cells in the human thymus. An ultrastructural study. Cell Tissue Res. 237: 227-237.

van Vliet, E., Melis, M. and van Ewijk, W. (1984) Monoclonal antibodies to stromal cell types of the mouse thymus. Eur. J. Immunol. 14: 524-529.

Volkmann, A., Zal, T. and Stockinger, B. (1997) Antigen-presenting cells in the thymus can negatively select MHC class II-restricted $\mathrm{T}$ cells recognizing a circulating self antigen. J. Immunol. 158: 693-706. 


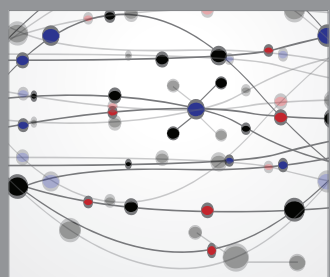

The Scientific World Journal
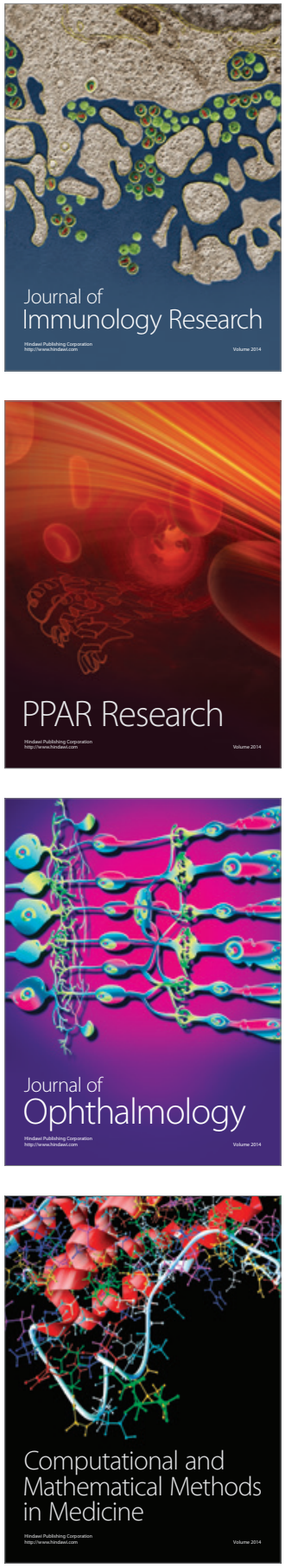

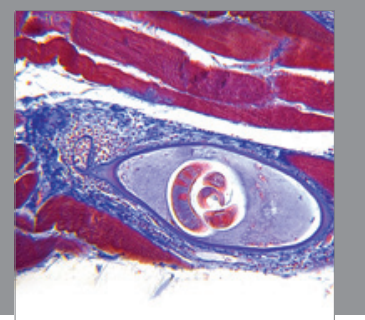

Gastroenterology

Research and Practice
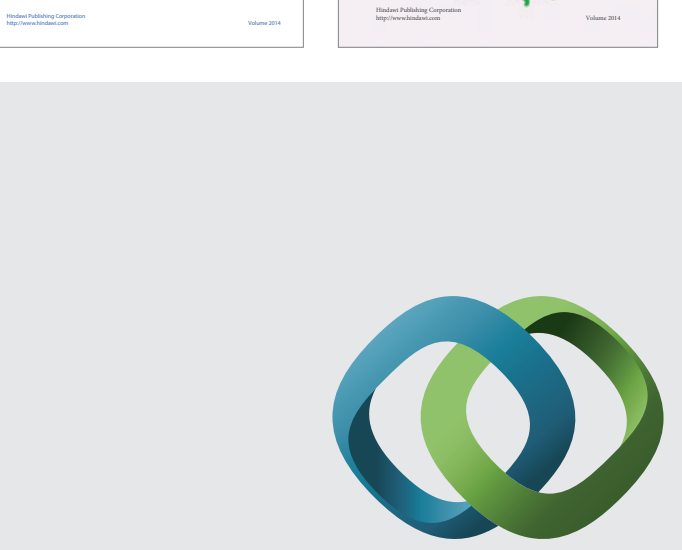

\section{Hindawi}

Submit your manuscripts at

http://www.hindawi.com
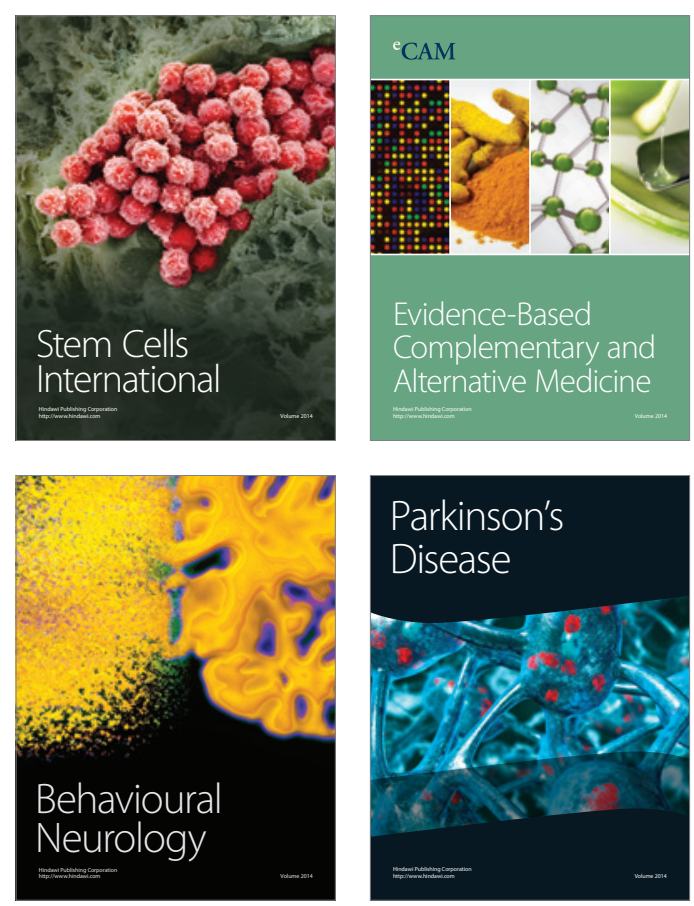

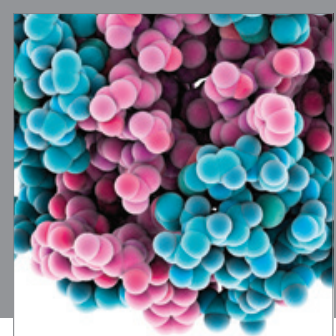

Journal of
Diabetes Research

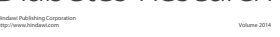

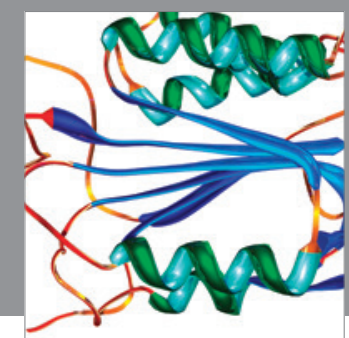

Disease Markers
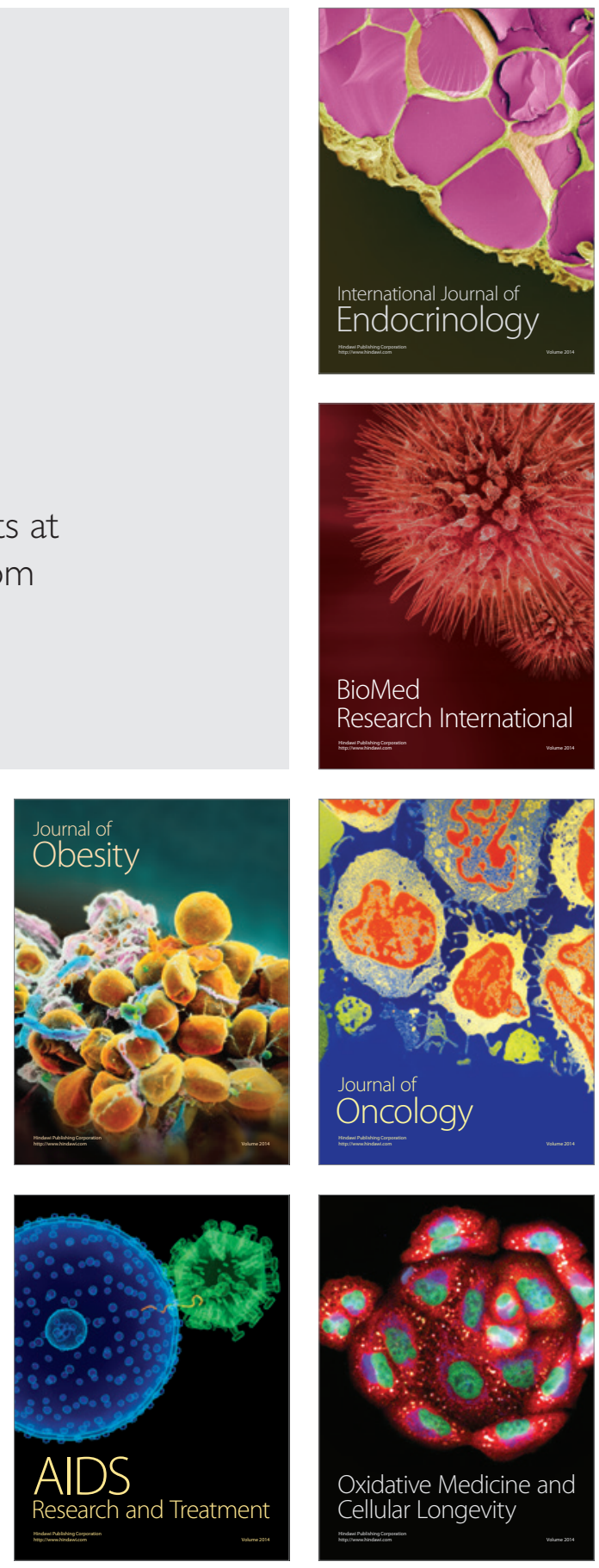